\title{
P2X Receptor Intermediate Activation States Have Altered Nucleotide Selectivity
}

\author{
Liam E. Browne and R. Alan North \\ Faculties of Medical and Human Sciences, and Life Sciences, University of Manchester, Manchester, M13 9PT, United Kingdom
}

Purinergic P2X receptors are widely distributed in the nervous system and are known to play roles in primary afferent transmission and central respiratory regulation. They are trimeric membrane proteins, with the extracellular domain that provides three intersubunit ATP binding sites. We expressed the rat P2X7 receptor in human embryonic kidney cells and measured membrane currents before and after photo-affinity labeling with the agonist 2' (3')-O-(4-benzoylbenzoyl)-ATP (BzATP). After tethering BzATP with ultraviolet light, a persistent current remained after washing out the agonist. Additional current could now be elicited by other nucleotides (CTP and ADP) that are not normally effective as P2X receptor agonists. Similar results were obtained at P2X2 receptors even without previous agonist tethering: exposure to low concentrations of ATP caused the receptor to become sensitive to activation by CTP and ADP. The results show that ATP binding to the first of the three binding sites causes a conformational change to an intermediate closed state that shows increased effectiveness of pyrimidine and diphosphate nucleotide analogs.

\section{Introduction}

Purinergic P2X receptors are a family of ion channels activated by extracellular ATP (Burnstock and Kennedy, 1985; North, 2002). The ATP is released from astrocytes and can have neuromodulatory roles at both presynaptic and postsynaptic sites (for review, see Khakh and North, 2012). These include primary afferent transmission (e.g., taste, bladder filling, baroreception), pain sensing, neurosecretion from hypothalamic neurons, and the central control of respiration (Khakh and North, 2012). Activation of P2X7 receptors by ATP is also a key step in the release of inflammatory cytokines from microglia primed with lipopolysaccharide (Ferrari et al., 1997). Accordingly, P2X receptors have been considered to be an attractive therapeutic target in diseases, including pain, stroke, and multiple sclerosis (Romagnoli et al., 2008; North and Jarvis, 2013).

The receptors are trimeric membrane proteins, as first inferred from functional studies on sensory neurons (Bean, 1990) and later demonstrated by native gel electrophoresis (Nicke et al., 1998), concatenation of subunits with a reporter mutation (Stoop et al., 1999), atomic force microscopy (Barrera et al., 2005), single molecule photobleaching (Richards et al., 2012), and x-ray crystallography (Kawate et al., 2009; Hattori and Gouaux, 2012). They form channels as homotrimers, although some sensory neuron receptors can assemble as heterotrimers (e.g., P2X1/5 and P2X2/3; North, 2002). The ATP binding sites

\footnotetext{
Received May 14, 2013; revised July 22, 2013; accepted Aug. 8, 2013.

Author contributions: L.E.B. and R.A.N. designed research; L.E.B. performed research; L.E.B. and R.A.N. analyzed data; L.E.B. and R.A.N. wrote the paper.

This work was supported by Wellcome Trust Grant 093140/Z/10/Z. We thank Laricia Bragg for molecule biology and Rosemary Gaskell for tissue culture.

The authors declare no competing financial interests.

Correspondence should be addressed to Prof. R. A. North, Faculty of Medical and Human Sciences, Michael Smith Building, University of Manchester, Oxford Road, Manchester, M13 9PT, UK. E-mail: r.a.north@manchester.ac.uk. DOI:10.1523/JNEUROSCI.2022-13.2013

Copyright $\odot 2013$ the authors $\quad 0270-6474 / 13 / 3314801-08 \$ 15.00 / 0$
}

are formed at the interfaces between two subunits (Wilkinson et al., 2006; Marquez-Klaka et al., 2007) situated in the large ectodomain of the protein, $\sim 4 \mathrm{~nm}$ from the outer surface of the lipid membrane (Kawate et al., 2009; Hattori and Gouaux, 2012; for review, see Khakh and North, 2012).

The crystallization of a trimeric ATP-bound, open zebrafish P2X4 receptor at $2.9 \AA$ shows three binding sites and indicates the amino acid residues involved in direct contact with the ATP molecule (Hattori and Gouaux, 2012): these conform well to the previous interpretations from extensive work using mutagenesis and functional expression (Browne et al., 2010; Evans, 2010; Khakh and North, 2012). However, three ATP molecules do not bind simultaneously to the symmetrical trimer, and there is cooperativity in the relationship between ATP concentration and current through the open channel (Bean, 1990; Ding and Sachs, 1999; Jiang et al., 2003; Yan et al., 2010; Bhargava et al., 2012). This implies that the binding of the first molecule causes conformational changes that affect the binding of the second and third. The purpose of the present study was to investigate the molecular mechanism of channel opening by observing the changes in the second and third binding sites that occur during stepwise activation of the receptor. In the first approach, we used photoactivation to tether an agonist to a fraction of the binding sites in P2X7 receptors. In the second method, we studied the effects of application of nucleotides other than ATP on P2X2 receptors, comparing their effects when applied alone with their actions during a concurrent application of ATP.

The P2X receptor is considered to be highly selective for ATP as the agonist. However, the extracellular milieu of the nervous system contains several nucleotides other than ATP (particularly ADP, adenosine, and UTP), and this raises the possibility that such intermediate states might be more readily activated by such ligands. Thus, the final aim of the work was to determine whether such altered selectivity might be sufficient to affect the physiolog- 
ical role of extracellular nucleotides acting on neurons and glia (Khakh and North, 2012).

\section{Materials and Methods}

The wild-type $\mathrm{P} 2 \mathrm{X} 7$ receptor cDNA $(50 \mathrm{ng} / \mathrm{ml}$ ) or P2X2 receptor cDNA $(100 \mathrm{ng} / \mathrm{ml})$ was transiently coexpressed together with pEGFP-N1 (100 $\mathrm{ng} / \mathrm{ml}$ ) in HEK 293 cells (using Lipofectamine 2000; Invitrogen). Cells were seeded on borosilicate glass coverslips (Agar Scientific). Whole-cell patch-clamp recordings were made at room temperature from 24 to $48 \mathrm{~h}$ after transfection (Cao et al., 2009). Recording pipettes were pulled from borosilicate glass (Harvard Apparatus) and had resistances of 2-4 M $\Omega$. The intracellular (pipette) solution comprised the following (in mM): 147 $\mathrm{NaCl}, 10$ EGTA, and 10 HEPES. The extracellular solution contained the following (in mM): $147 \mathrm{NaCl}, 2 \mathrm{KCl}, 2 \mathrm{CaCl}_{2}, 1 \mathrm{MgCl}_{2}, 10 \mathrm{HEPES}$, and 13 glucose. All solutions were maintained at $285-315 \mathrm{mOsm} / \mathrm{L}$ and $\mathrm{pH}$ 7.3. Currents were recorded with an EPC10 amplifier using Patchmaster software (HEKA Elektronik) from a holding potential of $-60 \mathrm{mV}$ unless stated otherwise. The data were low-pass filtered at $3 \mathrm{kHz}$, sampled at 1 $\mathrm{kHz}$, and subsequently Gaussian filtered offline at $0.2 \mathrm{kHz}$. Agonists and other compounds were applied using an RSC-160 rapid perfusion system (Bio-Logic) and Perfusion Pencil (Digitimer).

In the case of $\mathrm{P} 2 \mathrm{X} 7$ receptors, 1 min after attaining the whole-cell recording configuration, an initial "facilitating" application of $2^{\prime}\left(3^{\prime}\right)-O$ (4-benzoylbenzoyl)-ATP (BzATP) (100 $\mu \mathrm{M}, 40 \mathrm{~s})$ was made: during this period, a typical biphasic current was observed that developed to a steady state. After a wash period of 1 - 2 min, additional applications of BzATP gave highly reproducible responses, which showed monophasic rising phases and rapid washouts. Illumination for photoaffinity tethering was applied using a continuously operating $100 \mathrm{~W}$ mercury lamp with Nikon Fluor $40 \times / 0.75$ numerical aperture (NA) objective (power output, $\sim 0.6$ $\mathrm{mW} / \mathrm{mm}^{2}$ through a $355 / 50 \mathrm{~nm}$ excitation filter). Light was bandpass filtered to minimize cellular photodamage and heat, and the source was controlled by a shutter.

Fluorescent images were acquired using a Nikon laser-scanning C1 confocal microscope using a Nikon Fluor $40 \times / 0.75$ NA objective. Fluorescence excitation and detection were with a helium/neon $543 \mathrm{~nm}$ laser line with $570 \mathrm{~nm}$ long-pass emission filter. Ethidium was used at $25 \mu \mathrm{M}$, and photobleaching was $<5 \%$. The $\mathrm{C} 1$ confocal and RSC- 160 were both triggered by telegraphing outputs of the EPC10 amplifier.

Electrophysiological data were analyzed using FitMaster (HEKA Elektronik), Axograph X (Molecular Devices), and Prism 4 (GraphPad Software) software. Pooled data are given as the mean \pm SEM. Tests for statistical significance were performed using nonparametric ANOVA. The Hill equation $I / I_{\max }=[A]^{n} /\left([A]^{n}+\mathrm{EC}_{50}{ }^{n}\right.$ ) (where $[A]$ is the agonist concentration causing current $I, \mathrm{EC}_{50}$ is the agonist concentration causing half the maximal current $I_{\max }$, and $n$ is the Hill coefficient) reduces to $I=[A]^{n}$ for small values of $I$. Therefore, we estimated Hill coefficients from the limiting slope of the plot between $\log$ (current) and $\log$ (concentration), as described previously (Jiang et al., 2003).

\section{Results \\ Ultraviolet light tethers the agonist BzATP to the $\mathrm{P} 2 \mathrm{X} 7$ receptor}

Most P2X receptors are activated by ATP at nanomolar to micromolar concentrations, but the P2X7 receptor is less sensitive than the others: the concentration causing half-maximal membrane current $\left(\mathrm{EC}_{50}\right.$ ) is $\sim 1 \mathrm{~mm}$ (North, 2002). The analog BzATP is more potent $\left(\mathrm{EC}_{50}\right.$ of $\sim 30 \mu \mathrm{M}$ ) and has been widely used experimentally to activate $\mathrm{P} 2 \mathrm{X} 7$ receptors. Figure $1 A$ shows a typical membrane current evoked by applying BzATP $(100 \mu \mathrm{M}, 30 \mathrm{~s})$ to a HEK 293 cell voltage clamped at $-60 \mathrm{mV}$ (black trace). The current declines back to zero within $\sim 10 \mathrm{~s}$ of terminating the application. The superimposed blue trace shows that, when BzATP is reapplied but coincident with ultraviolet (UV) irradiation, the peak current is not different but channel closure after agonist washout is much impaired (the persistent current, orange arrow).
The persistent current that followed application of BzATP $(100 \mu \mathrm{M})$ together with UV light continued until the cell showed formation of membrane blebs, and the seal to the recording pipette was lost (Virginio et al., 1999). With shorter applications of UV light, the sustained current was of lower amplitude (Fig. $1 B, C$ ) but still persisted for several minutes (Fig. 1D). A concentration of BzATP that was too low to evoke any measurable current $(3 \mu \mathrm{M},<10 \mathrm{pA})$ became effective when paired with UV irradiation (Fig. 1E). UV irradiation alone had no effect, there was no effect of BzATP and UV light on cells that did not express $\mathrm{P} 2 \mathrm{X} 7$ receptors, and currents evoked by ATP were unaffected by UV irradiation (Fig. $1 H-J$ ). We interpret these results to indicate that UV light "tethers" the agonist BzATP at its binding site. We observed similar although slower and less complete tethering with BzATP on cells expressing rat $\mathrm{P} 2 \mathrm{X} 2$ or $\mathrm{P} 2 \mathrm{X} 4$ receptors.

Activation of P2X7 receptors can be monitored not only as membrane current but also by the uptake of ethidium and related dyes, which become fluorescent when they bind to intracellular nucleic acids (Steinberg et al., 1987; Surprenant et al., 1996): we showed recently that these dyes can directly permeate the open P2X7 receptor channel (Browne et al., 2013). We found that coapplication of BzATP $(300 \mu \mathrm{M})$ and UV light for $10 \mathrm{~s}$ resulted in sustained dye uptake, as detected when ethidium was added $30 \mathrm{~s}$ later (Fig. $1 K, L$ ). The ethidium uptake was less when the UV irradiation was only $3 \mathrm{~s}$, and it was absent when ATP ( $5 \mathrm{~mm})$ was used in place of BzATP.

The properties of the receptors that remained available after tethering were examined by measuring membrane currents elicited by additional applications of BzATP. Figure $1 F$ shows six experiments, each with a different concentration of BzATP, in which the currents in different colors are superimposed for display. In each experiment, BzATP was applied six times. The left panel shows the first group of three applications: at the test concentration $(x=1,3,10,30,100$, or $300 \mu \mathrm{M} ; 5 \mathrm{~s})$, second at $100 \mu \mathrm{M}$ ( $5 \mathrm{~s}$, for normalization), and third again at the test concentration. The right panel shows the second group of three applications ( $\geq 60 \mathrm{~s}$ later), and, in this case, the second of the three applications (at $100 \mu \mathrm{M}$ ) was paired with UV irradiation. After this tethering, concentrations of BzATP ( 1 and $3 \mu \mathrm{M}$ ) that had no effect on resting $\mathrm{P} 2 \mathrm{X} 7$ receptors were now able to activate current. The corresponding concentration-response curves are shown in Figure $1 G$ : under control conditions, the limiting slope of the Hill plot (Fig. $1 G$ ) was $2.52 \pm 0.09$ (five concentrations tested, one per cell, $n=32$ ), whereas after UV irradiation, the slope was $0.73 \pm$ 0.09 ( six concentrations tested, one per cell, $n=44 ; p<0.0001$ ). This led to a great increase in sensitivity to lower concentrations of BzATP, although there was no change in the $\mathrm{EC}_{50}$ (control, $40 \pm 4 \mu \mathrm{M}, n=32$; after UV, $32 \pm 1 \mu \mathrm{M}, n=44 ; p>0.05)$. In other words, P2X7 receptors with one (or two) BzATP molecule tethered exhibited much reduced cooperativity in their activation by a subsequent application of BzATP.

\section{Competitive and noncompetitive $\mathrm{P} 2 \mathrm{X} 7$ antagonists discriminated by tethered BzATP}

3-[[5-(2,3-Dichlorophenyl)tetrazol-1-yl]methyl]pyridine (A438079) is a P2X7 receptor antagonist that blocks current evoked by BzATP in non-neuronal cells and interleukin- $1 \beta$ release from peripheral macrophages (Donnelly-Roberts and Jarvis, 2007; McGaraughty et al., 2007). A438079 reversibly inhibited currents evoked by BzATP $(300 \mu \mathrm{M})$ in HEK 293 cells expressing P2X7 receptors with an $\mathrm{IC}_{50}$ of $\sim 2 \mu \mathrm{M}$ (Fig. $2 A, C$ ). However, A438079 was ineffective to inhibit the sustained current that followed concurrent exposure to UV light and application of BzATP (Fig. 2B,C). Pre- 
A

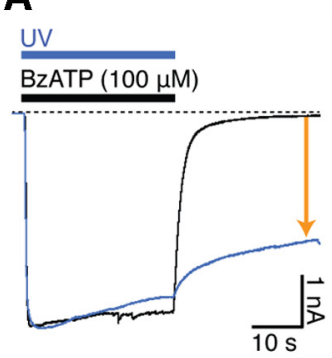

B

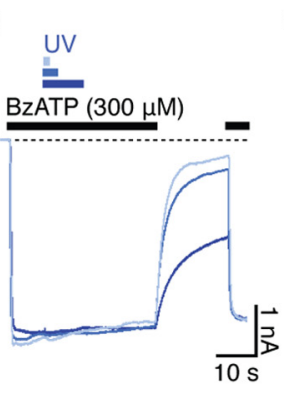

D

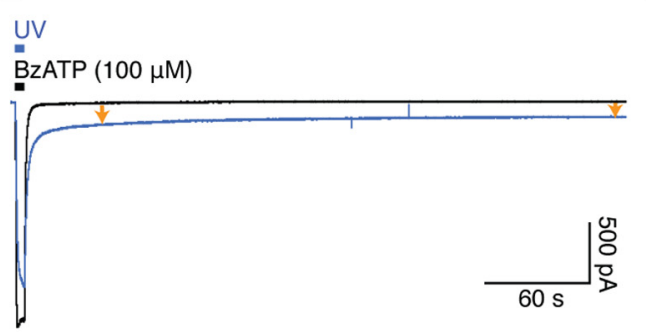

F
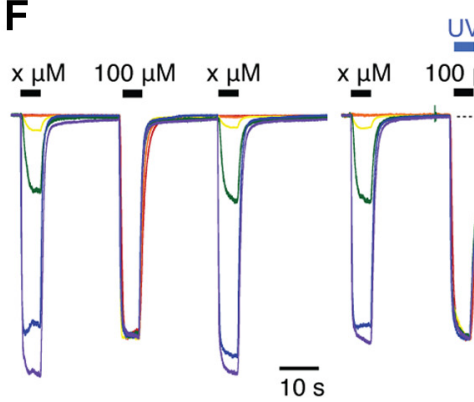

H

uv

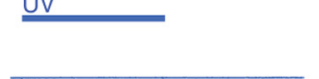

I

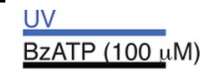

C

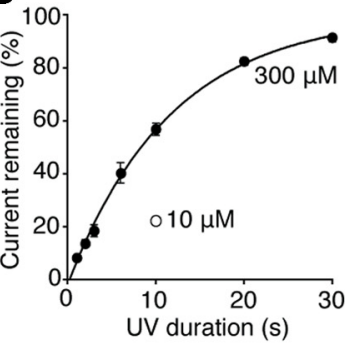

E

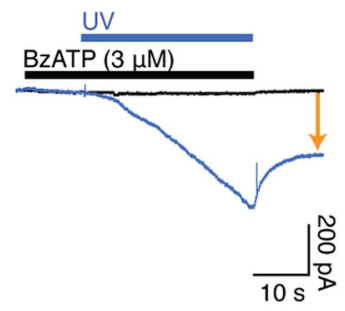

G

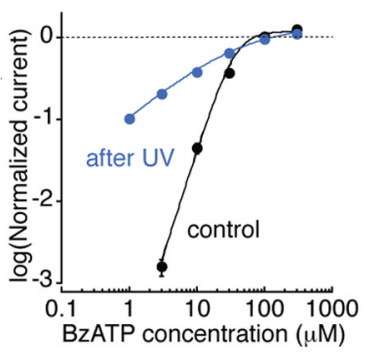

J

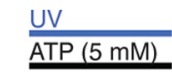

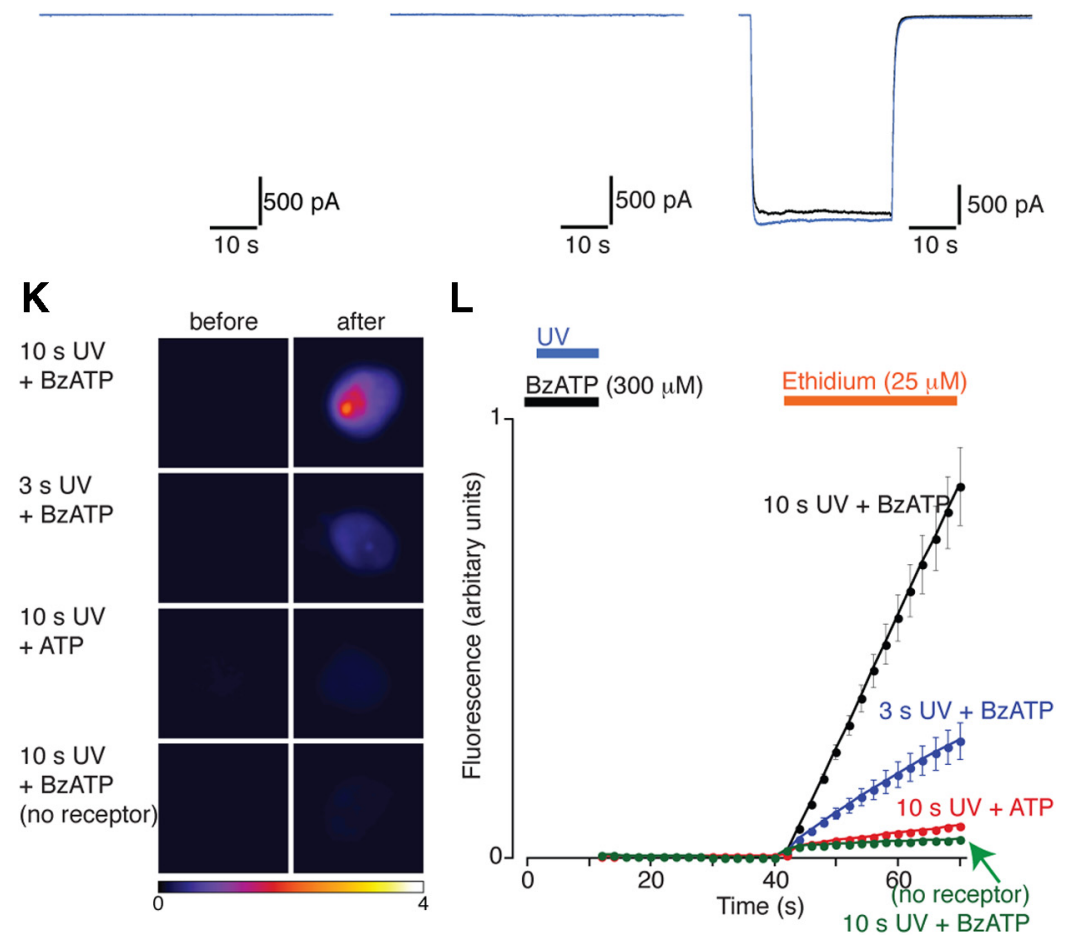

Figure 1. Covalently attached agonist causes irreversible activation of the $P 2 X 7$ receptor. $A, P 2 X 7$ receptor currents evoked by BzATP, without (black) and with (blue) UV irradiation. After irradiation, current continues to flow after BzATP application is discontinued (orange arrow). $\boldsymbol{B}$, Superimposed traces showing that the fraction of receptors that remain activated after washout

vious and concomitant A438079 (10 $\mu \mathrm{M})$ blocked the current evoked by BzATP $(100 \mu \mathrm{M})$, but this block was slowly overcome by UV irradiation because the BzATP association rate greatly increased after tethering (Fig. 2D). This indicates that A438079 acts as a competitive antagonist.

Zinc blocks currents through P2X7 receptors (Virginio et al., 1997; Liu et al., 2008). We used a maximal concentration of BzATP $(300 \mu \mathrm{M})$ to evoke currents and found that $50 \%$ inhibition was caused by $30 \mu \mathrm{M}$ zinc (Fig. 2E,G). The sustained current that followed coapplication of BzATP and UV light was inhibited by zinc to a similar extent (Fig. $2 F, G$ ). Previous and concomitant application of zinc (300 $\mu \mathrm{M})$ prevented any current from being evoked by BzATP (100 $\mu \mathrm{M}, 20 \mathrm{~s})$ and UV light: however, tethering had clearly occurred in the presence of zinc, because a sustained inward current developed when the zinc was washed out (Fig. $2 H$ ). These experiments indicate that zinc is not acting at the ATP binding site.

\section{$\leftarrow$}

of BZATP depends on the duration of UV irradiation (1, 3, or $10 \mathrm{~s})$. A second application of BzATP (300 $\mu \mathrm{m}, 5 \mathrm{~s}$ ) evoked a maximal current. C, The proportion of channels with tethered agonist increases exponentially with the duration of irradiation. The amplitude of current remaining after washout of BZATP is shown as a fraction of the maximum current. Error bars (SEM for 6-7 cells) are shown when they exceed the symbol size. $\boldsymbol{D}, \mathrm{A}$ brief application of BzATP (5s) evokes a current that continues to flow for several minutes if coapplied with UV irradiation (blue trace, orange arrows). $\boldsymbol{E}$, A concentration of BzATP $(3 \mu \mathrm{M})$ that is too low to elicit any membrane current $(<10 \mathrm{pA})$ becomes effective when paired with UV irradiation. $\boldsymbol{F}$, Currents recorded from six cells, superimposed for display. In each experiment, BzATP was applied three times. The first, third (left), fourth, and sixth (right) applications were at the same fixed concentration ( $1 \mu \mathrm{M}$, red; $3 \mu \mathrm{M}$, orange; $10 \mu \mathrm{M}$, yellow; $30 \mu \mathrm{m}$, green; $100 \mu \mathrm{m}$, blue; $300 \mu \mathrm{m}$, purple). The second (left) and fifth (right) applications were at $100 \mu \mathrm{m}$ BzATP (for normalization). Left shows controls. Right shows effect of $5 \mathrm{~s}$ UV irradiation (blue bar) coapplied with BzATP $(100 \mu \mathrm{M})$. G, BzATP dose-response curves without (black) and with (blue) UV irradiation measured from amplitudes of currents resulting from fourth and sixth applications (see $\boldsymbol{F}$ ). Logarithmic axes. $\boldsymbol{H}$, UV light alone has no effect on HEK 293 cells expressing P2X7 receptors. I, BzATP and UV light has no effect of HEK 293 cells that have not been transfected to express P2X7 receptors. J, ATP evokes a large current in HEK 293 cells transfected with $\mathrm{P} 2 \mathrm{X} 7$ receptor, but this is not made irreversible by concomitant UV light. $\boldsymbol{K}$, Representative images of cellular fluorescence after uptake of ethidium. Agonist was applied for $12 \mathrm{~s}$ while the cell was UV irradiated for 3 or $10 \mathrm{~s}$. Ethidium was applied for $30 \mathrm{~s}$ after washout of free agonist. Scale bar, 10 $\mu \mathrm{m}$. $L$, Time course of ethidium fluorescence shows that the cell only becomes permeable to ethidium when the agonist was covalently attached to the P2X7 receptor. Error bars are SEM for five to seven cells in each case. 


\section{Nucleotides other than ATP can activate agonist-tethered \\ $\mathrm{P} 2 \mathrm{X} 7$ receptors}

$\mathrm{P} 2 \mathrm{X}$ receptors require an agonist with both an adenine moiety and at least three phosphates attached sequentially at the $5^{\prime}$ position: they are not activated by CTP, UTP, GTP, or ITP, nor by ADP, AMP, or adenosine. We found that this selectivity was relaxed after agonist tethering, in which both ADP (Fig. 3A) and CTP (Fig. $3 B$ ) caused inward currents. AMP, GTP, and UTP were effective to a lesser degree (Fig. $3 A-C)$. CTP (3 mM) evoked a current that was $24 \%$ of the amplitude of the remaining current that was caused by BzATP (100 $\mu \mathrm{M}$; Fig. $3 C)$. The increase in effectiveness of ADP was observed at all concentrations tested (Fig. 3D). These results indicate that $\mathrm{P} 2 \mathrm{X} 7$ receptors with one (or two) BzATP molecule tethered show an altered selectivity with respect to activation by nucleotides.

\section{$\mathrm{P} 2 \mathrm{X} 2$ receptors are also activated by other nucleotides after priming ATP application}

The observation that $\mathrm{P} 2 \mathrm{X} 7$ receptors become sensitive to some other nucleotides when partially activated by tethered BzATP suggested that a similar phenomenon might occur without tethering. We tested this at $\mathrm{P} 2 \mathrm{X} 2$ receptors rather than $\mathrm{P} 2 \mathrm{X} 7$ receptors, because they are activated by lower concentrations of ATP.

Nucleotides with different bases that evoked no inward current when applied alone (CTP $10 \mu \mathrm{M}$, UTP $300 \mu \mathrm{M}$, and ITP $300 \mu \mathrm{M}$ ) were able to elicit an inward current when they were applied in the concomitant presence of a low concentration of ATP ( $3 \mu \mathrm{M}$; Fig. $4 A, B$ ). ATP, when applied at a concentration that evoked no current $(0.6 \mu \mathrm{M})$, increased the effectiveness of concomitantly applied CTP (Fig. $4 D$ ), reducing the Hill coefficient from 2.1 to 1.5 ( $n=7$ cells). Conversely, application of CTP $(10 \mu \mathrm{M})$ increased the effectiveness of ATP and reduced the Hill coefficient from 3.1 to 2.4 ( $n=6-7$ cells). These results suggest that occupancy of one of three binding sites by ATP causes a conformational change in the other binding sites so as to increase the effectiveness of other nucleotides to bind and open the channel. We observed essentially similar results for some analogs in which the length of the $5^{\prime}$ phosphate chain was reduced (ADP, AMP, CDP, and CMP; Fig. 4A,C).

The lysine residue at position 69 of the P2X2 receptor is critical for agonist action. From the crystal structure of the zebrafish P2X4 receptor, its $\varepsilon$-nitrogen atom likely makes direct contact with oxygen atoms of the $\gamma$ phosphate (Hattori and Gouaux,

B

E

$\mathbf{F}$
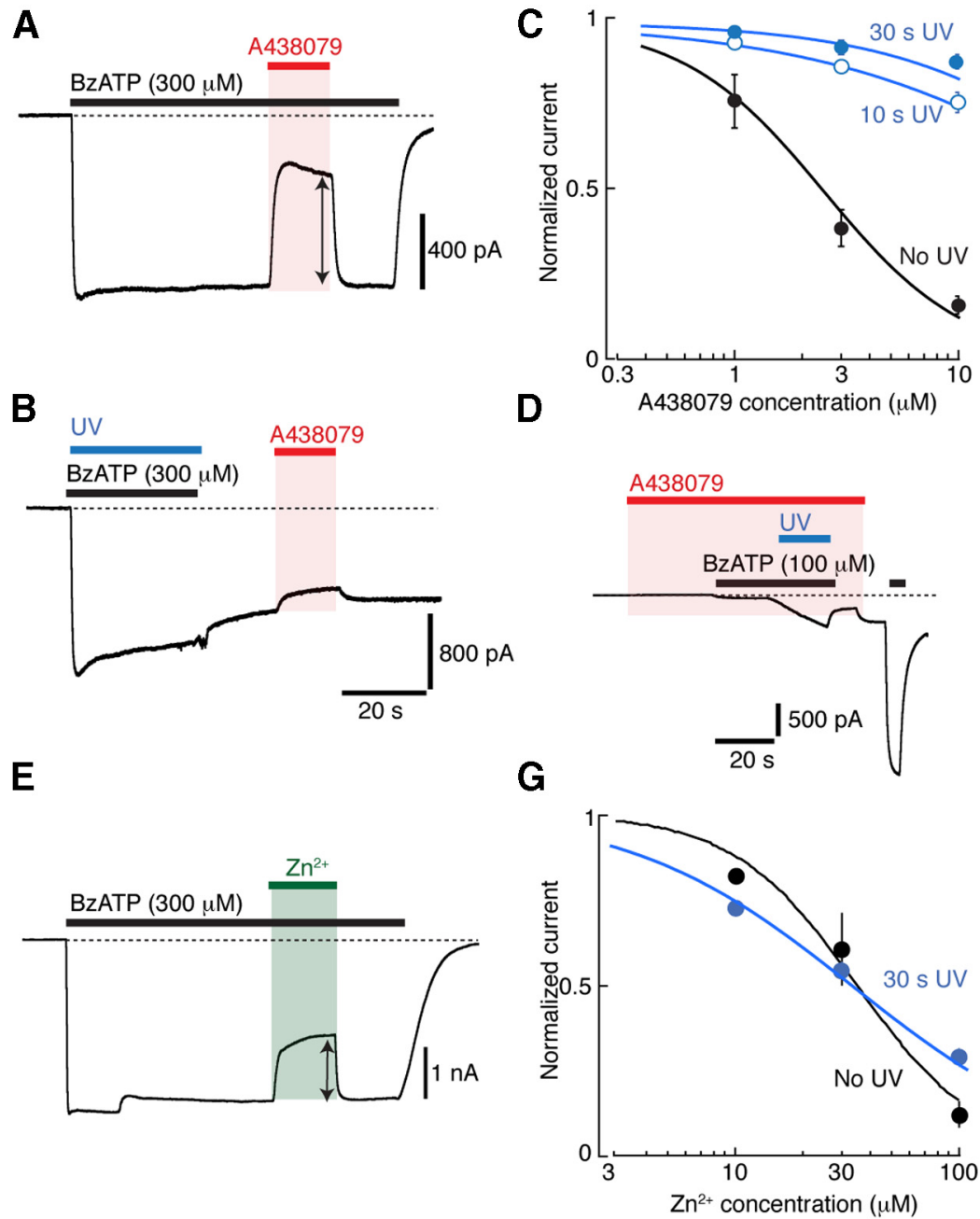

H
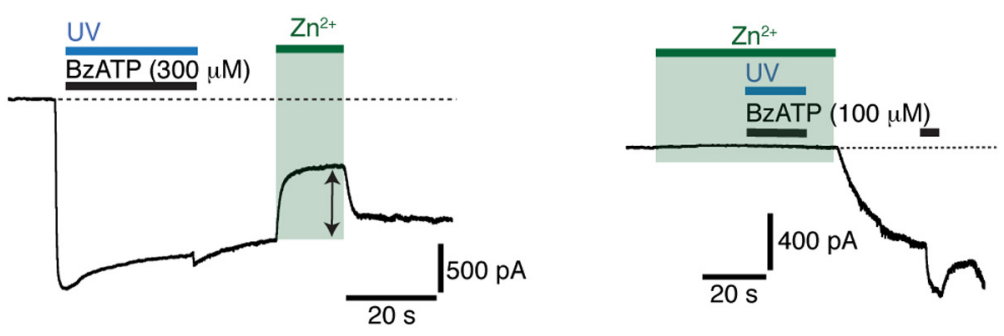

Figure 2. Competitive and noncompetitive P2X7 receptor antagonists distinguished by tethered agonist. $A$, Competitive inhibition by A438079 (3 $\mu \mathrm{M})$ in the presence of BzATP. B, A438079 (3 $\mu \mathrm{m})$ has very little effect to inhibit current evoked by tethered BzATP. C, Concentration-response curves for inhibition by A438079 when BzATP is tethered using 10 or 30 s UV irradiation (blue) compared with that for untethered BzATP (black). Error bars are SEM for six to seven cells. D, Previous application of A438079 (10 $\mu \mathrm{M})$ prevents BzATP from evoking any current. UV irradiation then elicits a slowly developing current as BzATP molecules become tethered when they bind, and this current persists when BzATP (and A438079) application is discontinued. An additional brief (5s) application of BzATP $(100 \mu \mathrm{m})$ indicates the maximal current after washout of A438079. E, Noncompetitive inhibition by $\mathrm{Zn}^{2+}(30$ $\mu \mathrm{m})$ in the presence BzATP. $\boldsymbol{F}, \mathrm{Zn}^{2+}(30 \mu \mathrm{M})$ also inhibits current evoked by tethered BzATP. G, Concentration-response curves for inhibition by $\mathrm{Zn}^{2+}$ shows that inhibition is little different whether or not BzATP is tethered with UV irradiation (15s). Error bars are shown $(S E M, n=6)$ when they exceed the size of the symbol. $\boldsymbol{H}$, Previous application of $Z n^{2+}(300 \mu \mathrm{m})$ prevents any current from BzATP. However, UV light has effectively tethered the BzATP because the current develops when the $Z n^{2+}$ is washed out. A second brief application of BzATP was used to evoke a maximal current. The slower development of the current after washout of $\mathrm{Zn}^{2+}$ might suggest a different binding orientation for BzATP in the closed versus the open receptor $(\boldsymbol{E}, \boldsymbol{F})$.
2012). We used a concatenated cDNA that encoded a trimeric receptor with one Lys ${ }^{69}$ residue mutated to alanine, thereby eliminating ATP binding at one of the three sites (Stelmashenko et al., 2012): such receptors can be readily activated by ATP (Stelmashenko et al., 2012). We found that CTP also evoked currents in 
A

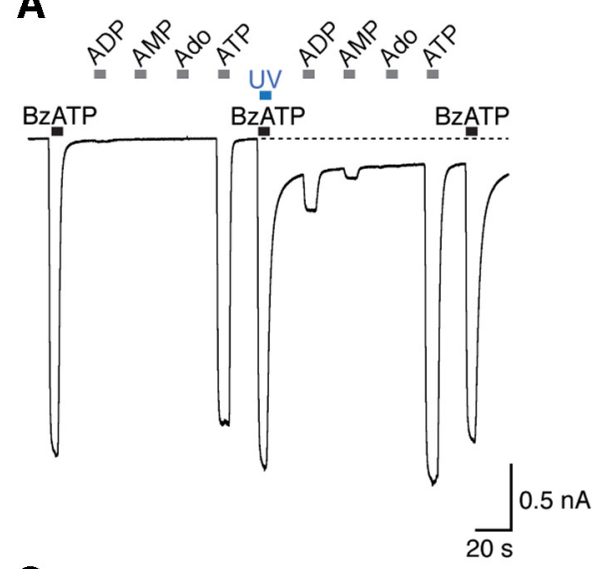

B
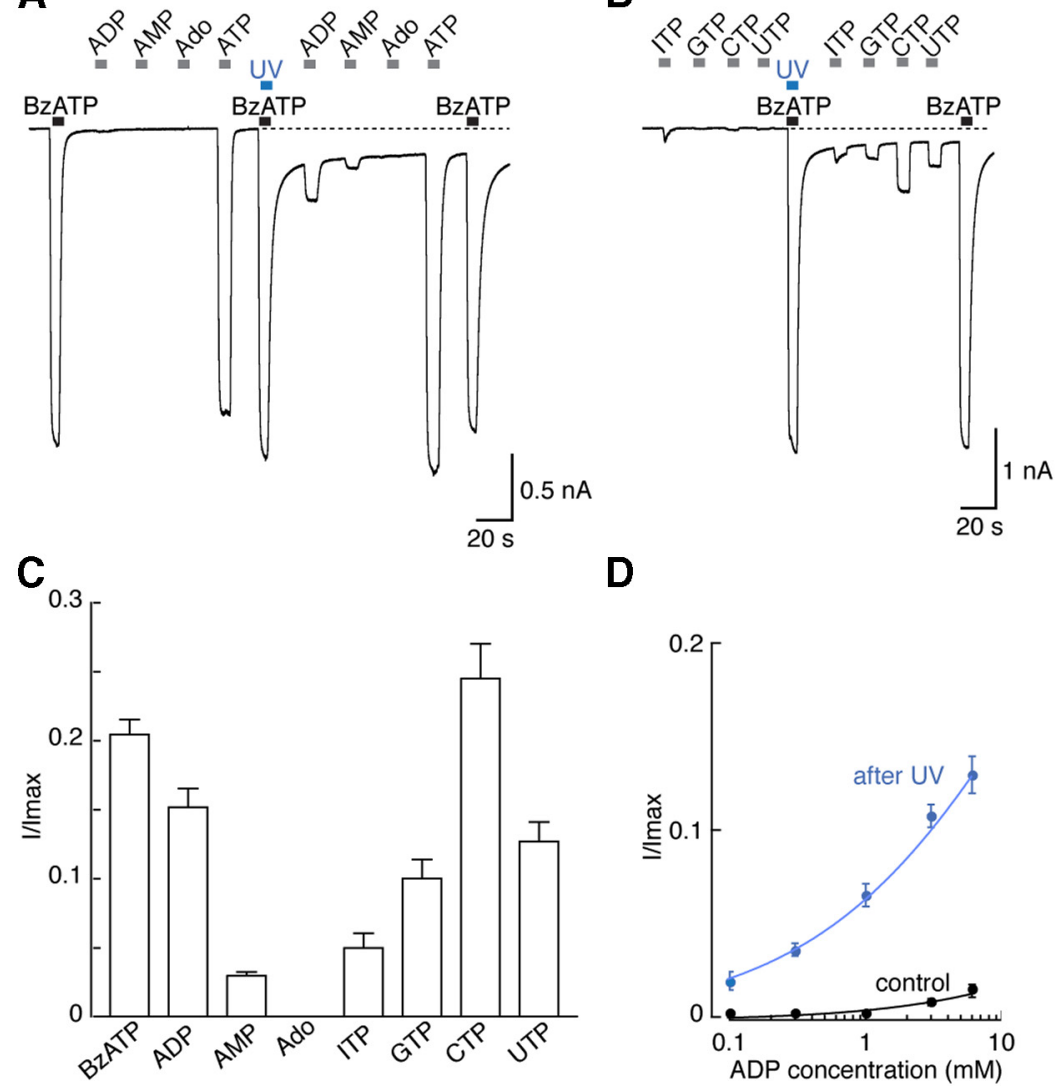

$\mathbf{D}$

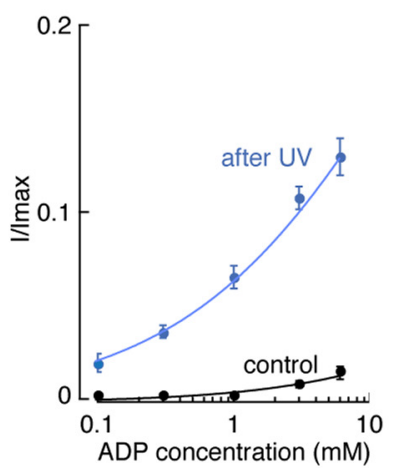

Figure 3. P2X7 receptors become sensitive to other nucleotides after BzATP tethering. $A$, Application of BzATP $(100 \mu \mathrm{m}, 5 \mathrm{~s})$ evokes a reversible current (maximal), but ADP and adenosine (Ado) are ineffective (each at $3 \mathrm{~mm}, 5 \mathrm{~s}$ ). ATP concentration was 3 $\mathrm{mm}$. A second application of BzATP $(100 \mu \mathrm{M}, 5 \mathrm{~s})$ is paired with UV irradiation, and this results in a sustained current. Application of $\operatorname{ADP}(3 \mathrm{~mm}, 5 \mathrm{~s})$ now evokes an additional inward current. $\boldsymbol{B}$, A similar experiment showing that the P2X7 receptor becomes sensitive to CTP and other nucleotides after BzATP tethering. ITP, GTP, CTP, and UTP at $3 \mathrm{~mm}, 5 \mathrm{~s} ;$ BzATP at $100 \mu \mathrm{m}, 5$ s. C, Summary from experiments such as those shown in $\boldsymbol{A}$ and $\boldsymbol{B}$. The column for BzATP shows results with $3 \mu \mathrm{m}$; concentrations of other agonists were as for $\boldsymbol{A}$ and $\boldsymbol{B}$. Columns show mean \pm SEM for $6-14$ cells. $\boldsymbol{D}$, Concentration-response curve for ADP applied before (black) and after (blue) tethering BzATP with UV irradiation, in the same five cells. Ordinate is fraction of maximal current evoked by BzATP $(100 \mu \mathrm{m})$.

these receptors, as long as they were primed by a low concentration of ATP (Fig. $4 F, G$ ). This suggests that ATP binding to one binding site is sufficient to increase the effectiveness of CTP at the second site.

\section{Discussion}

Benzophenone analogs of ATP have been used widely for the photoaffinity labeling of proteins that bind ATP. The $\alpha, \beta$ unsaturated carbonyl can form a diradical triplet state when excited with UV light. The triplet state can abstract a hydrogen atom from a nearby carbon-hydrogen bond on the receptor protein (Bayley and Knowles, 1977), typically from a C $\alpha$ atom (Dormán and Prestwich, 1994). At P2X receptors, benzophenone substitution at the $2^{\prime}$ or $3^{\prime}$ oxygen of ATP does not itself greatly alter agonist activity, and the crystal structure of the ATP-bound zebrafish $\mathrm{P} 2 \mathrm{X} 4$ receptor indicates that these two atoms are not directly involved in binding interactions (Hattori and Gouaux, 2012). The persistent current that followed UV irradiation together with BzATP application, together with the reduced Hill coefficient for activation of the remaining current, strongly indicates that UV light produces a "tethered" agonist by covalent attachment to the $\mathrm{P} 2 \mathrm{X}$ receptor close to the ATP binding pocket. Additional direct evidence that BzATP is tethered in the agonist binding pocket comes from our observation that the evoked currents are not blocked by the competitive antagonist A438079, although they remain sensitive to the noncompetitive antagonist zinc (Fig. 2).

A single receptor could have one to three BzATP molecules covalently tethered, and this would depend on the duration of UV irradiation as well as the agonist concentration (Fig. 1C) (it would also depend on the intensity of UV irradiation, but this was kept constant in the present experiments). The marked reduction in Hill coefficient from 2.6 to 0.7 after BzATP tethering (Fig. $1 G$ ) strongly suggests that the binding of a single agonist molecule is now sufficient to activate the remaining P2X7 receptors. More complex interpretations are possible, such as channel opening from both two-bound and three-bound states, in which case the binding of the third agonist molecule would effectively increase the probability of opening. This would be consistent with the gating model proposed by Yan et al. (2010) for rat P2X7 receptors. Conversely, a more complete analysis using global fitting of single-channel records found no evidence that $\mathrm{P} 2 \mathrm{X} 2$ receptors opened from a single or doubly liganded state (Ding and Sachs, 1999). Single-channel recordings in conjunction with BzATP tethering would be challenging, given the long durations of stable recording required.

Previous functional approaches at P2X receptors using agonist tethering have used 2-azido-ATP and BzATP. After exposure to UV light, the agonist action of ATP was reduced, and the results were interpreted to indicate that the photoaffinity labeling had caused receptor desensitization (Agboh et al., 2009). Bhargava et al. (2012) showed that the very weak partial agonist $\left(2^{\prime}, 4^{\prime}, 6^{\prime}\right.$ trinitrophenyl)-2',3'-O-ATP became more efficacious after BzATP tethering at P2X2/1 chimeric receptors. Jiang et al. (2011) tethered an ATP analog containing a sulfhydryl reactive moiety [8-thiocyano-ATP (NCS-ATP)] to a cysteine residue introduced into the $\mathrm{P} 2 \mathrm{X} 2$ receptor by mutagenesis. In the case of P2X2[L186C], the disulfide attachment through the thiocyanate on the 8 position on the adenine ring likely brings the ATP moiety into a position very similar to that observed in the ATP-bound open-channel structure (Hattori and Gouaux, 2012). The attached NCS-ATP did not itself open the channel, although it potentiated ATP-evoked currents and also made the channel sensitive to activation by zinc (Jiang et al., 2012a). It is known that formation of the zinc binding site requires "jaw closure" in which the H120 on head domain of one subunit approximates H213 on the dorsal fin of a different subunit (Nagaya et al., 2005; Tittle et al., 2007; Jiang et al., 2012b), so this implies that NCS-ATP conjugation (perhaps at only one or two of the three binding pockets) produces an intermediate, less stable, closed state from which full opening can readily proceed. A similar observation was made 
previously for the pore mutation P2X2[T339S] (Cao et al., 2007, 2009; Jiang et al., 2011). In contrast, our present results with BzATP are on $\mathrm{P} 2 \mathrm{X} 7$ receptors without any introduced mutations. They indicate that the agonist is free to bind and unbind in the binding pocket, but the flexible tether has the effect of greatly increasing the microscopic association constant.

The second main finding of the experiments with BzATP tethering was the altered agonist selectivity after agonist tethering (Fig. 3). Thus, after partial tethering, the $\mathrm{P} 2 \mathrm{X} 7$ receptor became activated by either pyrimidine-based triphosphates (UTP and CTP) or ADP at concentrations that previously had little or no effect. We observed BzATP tethering to P2X2 receptors. This occurred more slowly than for the P2X7 receptor, and the interpretation of these results is complicated by the desensitization that occurs when the agonist was applied for several seconds (Bhargava et al., 2012). Therefore, we studied P2X2 receptors further without photoaffinity labeling but with simple coapplication of different agonists. Figure $4 A$ shows that $\mathrm{P} 2 \mathrm{X} 2$ receptors were activated by CTP, $\mathrm{UTP}$, and ADP when these ligands were coapplied with ATP but not when they were applied alone.

The more detailed studies with CTP on $\mathrm{P} 2 \mathrm{X} 2$ receptors indicated that the initial slope of the Hill plot was significantly less when it was applied together with a concurrent application of ATP, although that concentration of ATP $(0.6 \mu \mathrm{M})$ caused no detectable current when applied alone. These experiments suggest that very low concentrations of ATP occupy one of the three binding sites, fail to open the channel, but induce a conformational change that alters the remaining sites so that they become more sensitive to CTP. The similar observation with the concatenated receptors (Fig. 4F) suggests that this also occurs in a channel lacking a key component $\left(\right.$ Lys $\left.^{69}\right)$ in one its three binding sites.

An interaction between ATP and ADP at $\mathrm{P} 2 \mathrm{X} 7$ receptors has been reported previously by Chakfe et al. (2002), who found that ADP could evoke inward currents at $\mathrm{P} 2 \mathrm{X} 7$ receptors expressed in oocytes, which previously received a previous (priming) application of ATP. This occurred when the ATP priming concentration was too low to elicit any current (100 $\mu \mathrm{M}$ ), and the effect lasted for several minutes after a brief ( $10 \mathrm{~s}$ ) priming. However, we failed to observe any such prolonged effect in our present studies on HEK 293 cells: this suggests that, with oocyte ex-
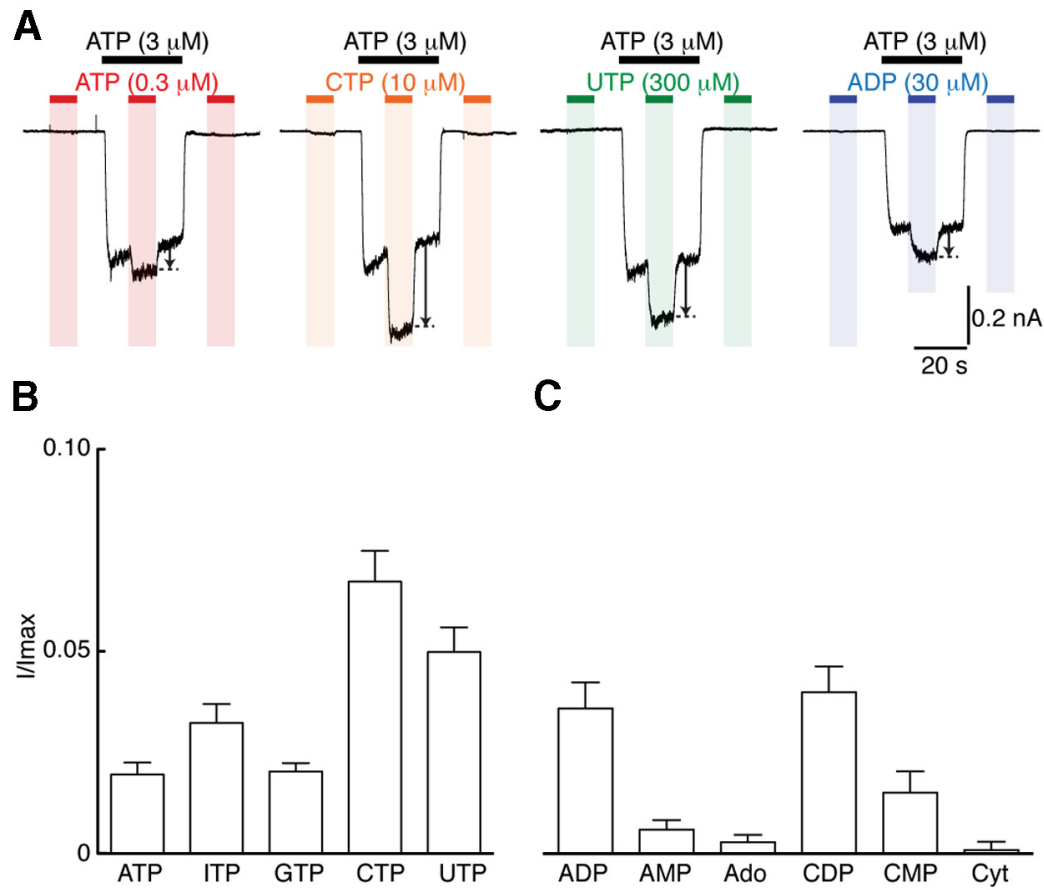

D

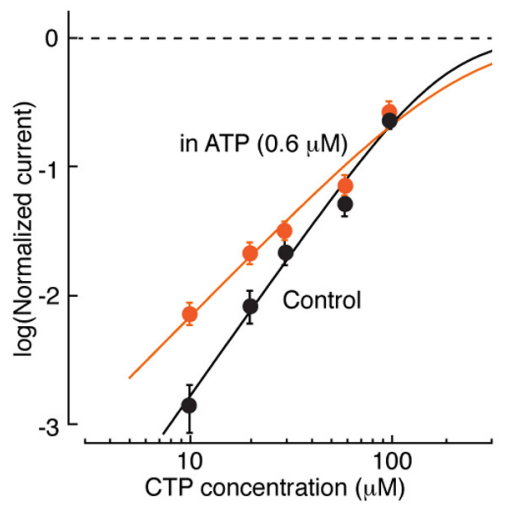

E

$\mathbf{F}$

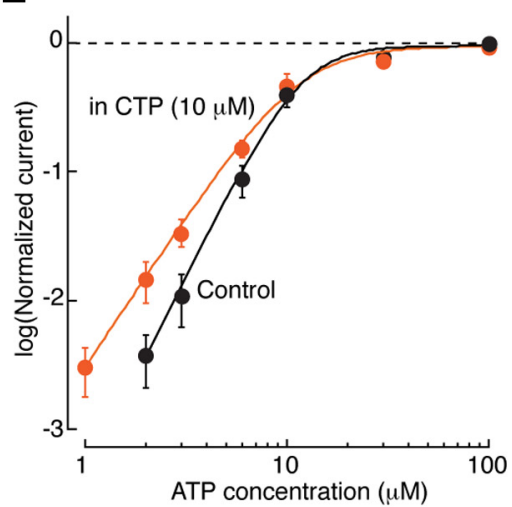

G

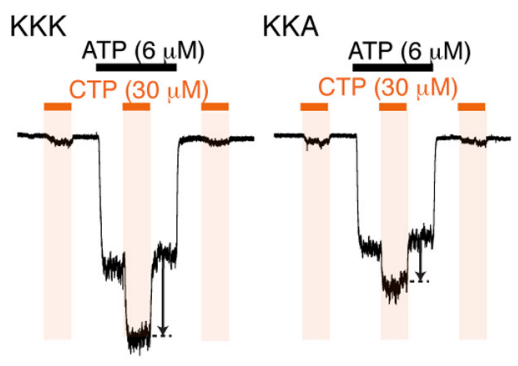

Figure 4. P2X2 receptors become sensitive to other nucleotides after ATP pretreatment. $A$, Application of ATP at $3 \mu \mathrm{m}$ results in the P2X2 receptor becoming sensitive to concentrations of ATP, CTP, UTP, and ADP that were otherwise ineffective. $B$, C, Summary of experiments such as those illustrated in $A$, where / is the additional current elicited (taking the current evoked by $3 \mu \mathrm{m}$ ATP as the baseline) indicated by the black arrow in $A$, and $I_{\text {max }}$ is the maximum current observed during a 2 s application of ATP (100 $\left.\mu \mathrm{M}\right)$. Concentrations for all compounds not shown in $\boldsymbol{A}$ were $300 \mu \mathrm{m}$. $\boldsymbol{D}$, Concentration-response curve for CTP at P2X2 receptors in the absence (black) and presence (orange) of a concentration of ATP that causes no detectable current when applied alone $(0.6 \mu \mathrm{M})$. $\boldsymbol{E}$, Concentration-response curve for ATP in the absence (black) and presence (orange) of a concentration of (TP that causes little or no detectable current when applied alone $(10 \mu \mathrm{M})$. $\boldsymbol{F}$, Increased sensitivity to (TP after ATP pretreatment is also shown by concatenated P2X receptors containing only two ATP-binding site lysine residues (at position 69). KKK has three concatenated wild-type subunits, KKA has K69A substitution in the third subunit; KAK has K69A substitution in second subunit. G, Summary of experiments illustrated in $\boldsymbol{F}$. Maximum current is that evoked by $300 \mu \mathrm{M}$ ATP. 
pression, the initial application of ATP signaled through some other pathway (such as a $\mathrm{P} 2 \mathrm{Y}$ receptor) to produce long-lasting changes in the properties of the $\mathrm{P} 2 \mathrm{X} 7$ receptors, perhaps by phosphorylation, as indeed proposed by Chakfe et al. (2002).

From the structure of the crystallized zebrafish P2X4 receptor (Hattori and Gouaux 2012), multiple hydrogen bonds are predicted between oxygen atoms of the $\gamma$ phosphate and charged nitrogen atoms (K70, K72 on chain A; R298, K316 on chain B: zebrafish P2X4 numbers), and the ribose and base interact hydrophobically with L217 and I232 (chain A) and L191 (chain B). Base specificity is determined by interactions between the $\mathrm{N}_{1}$ and $\mathrm{N}_{6}$ nitrogen atoms of the adenine, with the side chain and backbone oxygen atoms of T189 on chain A. Therefore, our findings imply that BzATP tethering to one site of the trimer results in substantial rearrangement of the unoccupied second (and third) binding pocket. In general terms, the unoccupied pocket(s) appears to become smaller, given that it loses its requirement for the $\gamma$ phosphate as well as becomes sensitive to smaller pyrimidines as distinct from purines (Hattori and Gouaux, 2012). Hattori and Gouaux (2012) provided a compelling explanation of why symmetrical, triply liganded P2X receptors are selective for ATP over other nucleotides. The present results imply that, when the first ATP molecule binds between the A and B subunits, a conformational change follows at the other two binding sites (between $\mathrm{B}$ and $\mathrm{C}$ and between $\mathrm{C}$ and $\mathrm{A}$ subunits) such that their high selectivity for ATP is lost. For P2X7 receptors, this is consistent with the interpretation of Yan et al. (2010) on the basis of their kinetic modeling with ATP as the ligand. According to their model, the $\mathrm{P} 2 \mathrm{X}$ receptor can exist in unliganded or mono-liganded closed states, as well as di-liganded and tri-liganded open states. All our experiments on P2X7 receptors were performed on receptors that had been "facilitated" (see Materials and Methods) or "sensitized" in the nomenclature of Yan et al. (2010). However, this did not itself render the receptors sensitive to CTP and ADP, and therefore, exact correspondence to the states of Yan et al. (2010) remains to be determined.

An alteration in agonist selectivity during progressive ligation has been shown previously for tetrameric cyclic nucleotide-gated channels. cAMP is normally ineffective at cGMP-gated channels, but it becomes effective after one or more cGMP moieties are covalently tethered (8-p-azidophenacylthio-cGMP used for tethering; Ruiz and Karpen, 1997). A conceptually analogous situation pertains for glycine-gated ion channels: in these homopentameric receptors, the residues contributing to the agonist binding site are provided by two adjacent subunits. Taurine is a weak partial agonist at three receptors because it is less able to bind to the closed, resting conformation of the receptor, but after binding of one (or more) glycine molecule, the receptor enters a conformationally distinct closed ("flipped") state, to which taurine more readily binds and thus opens the channel (Lape et al., 2008; Sivilotti, 2010). Our results suggest that a similar interpretation likely accounts for the increased effectiveness of CTP, $\mathrm{ADP}$, and other analogs after initial "priming" with a low concentration of ATP.

Together, the previous cognate literature and the present results are most readily explained if the binding of first ATP molecule induces a conformational change that (1) does not open the channel, (2) results in its slow dissociation from the channel, and (3) changes the conformation of the second and third subunits so that they can be activated by pyrimidine and diphosphate nucleotides that were previously very ineffective. The interpretation is consistent with the results of single-channel kinetics on P2X2 receptors that show a relatively long-lived singly bound state (un- binding of the first ATP molecule occurred 10-100 times more slowly than the other transitions; Ding and Sachs, 1999) and with the recent report of an intermediate closed state presented by Jiang et al. (2012a).

In a more physiological context, it is relevant that ATP is not the only nucleotide present in the extracellular milieu of the nervous system. ADP is readily formed by the action of ectonucleotidases (Zimmermann et al., 2012), and both UTP and ADP are preferred ligands at various P2Y receptors that are widely expressed in the CNS (von Kügelgen and Harden, 2011). The present finding that ADP, UTP, and CTP become effective at P2X receptors after previous binding of low concentrations of ATP therefore raises questions regarding the possible additional functional roles for mixtures of nucleotides found in the extracellular milieu of the nervous tissue.

\section{References}

Agboh KC, Powell AJ, Evans RJ (2009) Characterisation of ATP analogues to cross-link and label P2X receptors. Neuropharmacology 56:230-236. CrossRef Medline

Barrera NP, Ormond SJ, Henderson RM, Murrell-Lagnado RD, Edwardson JM (2005) Atomic force microscopy imaging demonstrates that P2X2 receptors are trimers but that $\mathrm{P} 2 \mathrm{X} 6$ receptor subunits do not oligomerize. J Biol Chem 280:10759-10765. CrossRef Medline

Bayley H, Knowles JR (1977) Photoaffinity labeling. Methods Enzymol 46: 69-114. CrossRef Medline

Bean BP (1990) ATP-activated channels in rat and bullfrog sensory neurons: concentration dependence and kinetics. J Neurosci 10:1-10. Medline

Bhargava Y, Rettinger J, Mourot A (2012) Allosteric nature of P2X receptor activation probed by photoaffinity labelling. Br J Pharmacol 167:1301-1310. CrossRef Medline

Browne LE, Jiang LH, North RA (2010) New structure enlivens interest in P2X receptors. Trends Pharmacol Sci 31:229-237. CrossRef Medline

Browne LE, Compan V, Bragg L, North RA (2013) P2X7 receptor channels allow direct permeation of nanometer sized dyes. J Neurosci 33: 3557-3566. CrossRef Medline

Burnstock G, Kennedy C (1985) Is there a basis for distinguishing two types of P2-purinoceptor? Gen Pharmacol 16:433-440. CrossRef Medline

Cao L, Young MT, Broomhead HE, Fountain SJ, North RA (2007) Thr339to-serine substitution in rat $\mathrm{P} 2 \mathrm{X} 2$ receptor second transmembrane domain causes constitutive opening and indicates a gating role for Lys308. J Neurosci 27:12916-12923. CrossRef Medline

Cao L, Broomhead HE, Young MT, North RA (2009) Polar residues in the second transmembrane domain of the rat $\mathrm{P} 2 \mathrm{X} 2$ receptor that affect spontaneous gating, unitary conductance and rectification. J Neurosci 29: 14257-14264. CrossRef Medline

Chakfe Y, Seguin R, Antel JP, Morissette C, Malo D, Henderson D, Séguéla P (2002) ADP and AMP induce interleukin- $1 \beta$ release from microglial cells through activation of ATP-primed P2X7 receptor channels. J Neurosci 22:3061-3069. Medline

Ding S, Sachs F (1999) Single channel properties of P2X2 purinoceptors. J Gen Physiol 113:695-720. CrossRef Medline

Donnelly-Roberts DL, Jarvis MF (2007) Discovery of P2X7 receptorselective antagonists offers new insights into $\mathrm{P} 2 \mathrm{X} 7$ receptor function and indicates a role in chronic pain states. Br J Pharmacol 151:571-579. CrossRef Medline

Dormán G, Prestwich GD (1994) Benzophenone photophores in biochemistry. Biochemistry 33:5661-5673. CrossRef Medline

Evans RJ (2010) Structural interpretation of P2X receptor mutagenesis studies on drug action. Br J Pharmacol 161:961-971. CrossRef Medline

Ferrari D, Chiozzi P, Falzoni S, Dal Susino M, Melchiorri L, Baricordi OR, Di Virgilio F (1997) Extracellular ATP triggers IL-1 beta release by activating the purinergic $\mathrm{P} 2 \mathrm{Z}$ receptor of human macrophages. J Immunol 159: 1451-1458. Medline

Hattori M, Gouaux E (2012) Molecular mechanism of ATP binding and ion channel activation in P2X receptors. Nature 485:207-212. CrossRef Medline

Jiang LH, Kim M, Spelta V, Bo X, Surprenant A, North RA (2003) Subunit arrangement in P2X receptors. J Neurosci 23:8903-8910. Medline 
Jiang R, Lemoine D, Martz A, Taly A, Gonin S, Prado de Carvalho L, Specht A, Grutter T (2011) Agonist trapped in ATP-binding sites of the P2X2 receptor. Proc Natl Acad Sci U S A 108:9066-9071. CrossRef Medline

Jiang R, Taly A, Lemoine D, Martz A, Specht A, Grutter T (2012a) Intermediate closed channel state(s) precede(s) activation in the ATP-gated P2X2 receptor. Channels (Austin) 6:398-402. CrossRef Medline

Jiang R, Taly A, Lemoine D, Martz A, Cunrath O, Grutter T (2012b) Tightening of the ATP-binding sites induces the opening of $\mathrm{P} 2 \mathrm{X}$ receptor channels. EMBO J 31:2134-2143. CrossRef Medline

Kawate T, Michel JC, Birdsong WT, Gouaux E (2009) Crystal structure of the ATP-gated P2X4 ion channel in the closed state. Nature 460:592-598. CrossRef Medline

Khakh BS, North RA (2012) Neuromodulation by extracellular ATP and P2X receptors in the CNS. Neuron 76:51-69. CrossRef Medline

Lape R, Colquhoun D, Sivilotti LG (2008) On the nature of partial agonism in the nicotinic receptor superfamily. Nature 454:722-727. CrossRef Medline

Liu X, Surprenant A, Mao HJ, Roger S, Xia R, Bradley H, Jiang LH (2008) Identification of key residues coordinating functional inhibition of P2X7 receptors by zinc and copper. Mol Pharmacol 73:252-259. CrossRef Medline

Marquez-Klaka B, Rettinger J, Bhargava Y, Eisele T, Nicke A (2007) Identification of an intersubunit cross-link between substituted cysteine residues located in the putative ATP binding site of the P2X1 receptor. J Neurosci 27:1456-1466. CrossRef Medline

McGaraughty S, Chu KL, Namovic MT, Donnelly-Roberts DL, Harris RR, Zhang XF, Shieh CC, Wismer CT, Zhu CZ, Gauvin DM, Fabiyi AC, Honore P, Gregg RJ, Kort ME, Nelson DW, Carroll WA, Marsh K, Faltynek CR, Jarvis MF (2007) P2X7-related modulation of pathological nociception in rats. Neuroscience 146:1817-1828. CrossRef Medline

Nagaya N, Tittle RK, Saar N, Dellal SS, Hume RI (2005) An intersubunit zinc binding site in rat P2X2 receptors. J Biol Chem 280:25982-25993. CrossRef Medline

Nicke A, Bäumert HG, Rettinger J, Eichele A, Lambrecht G, Mutschler E, Schmalzing G (1998) $\mathrm{P} 2 \mathrm{X}_{1}$ and $\mathrm{P} 2 \mathrm{X}_{3}$ receptors form stable trimers: a novel structural motif of ligand-gated ion channels. EMBO J 17:3016-3028. CrossRef Medline

North RA (2002) Molecular physiology of P2X receptors. Physiol Rev 82: 1013-1067. CrossRef Medline

North RA, Jarvis MF (2013) P2X receptors as drug targets. Mol Pharmacol 33:759-769. CrossRef Medline

Richards CI, Luong K, Srinivasan R, Turner SW, Dougherty DA, Korlach J, Lester HA (2012) Live-cell imaging of single receptor composition using zero-mode waveguide nanostructures. Nano Lett 12:3690-3694. CrossRef Medline

Romagnoli R, Baraldi PG, Cruz-Lopez O, Lopez-Cara C, Preti D, Borea PA, Gessi S (2008) The P2X7 receptor as a therapeutic target. Expert Opin Ther Targets 12:647-661. CrossRef Medline

Ruiz ML, Karpen JW (1997) Single cyclic nucleotide-gated channels locked in different ligand-bound states. Nature 389:389-392. CrossRef Medline

Sivilotti LG (2010) What single channel analysis tells us of the activation mechanism of ligand-gated channels: the case of the glycine receptor. J Physiol 588:45-58. CrossRef Medline

Steinberg TH, Newman AS, Swanson JA, Silverstein SC (1987) ATP4- permeabilizes the plasma membrane of mouse macrophages to fluorescent dyes. J Biol Chem 262:8884-8888. Medline

Stelmashenko O, Lalo U, Yang Y, Bragg L, North RA, Compan V (2012) Activation of trimeric $\mathrm{P} 2 \mathrm{X} 2$ receptors by fewer than three ATP molecules. Mol Pharmacol 82:760-766. CrossRef Medline

Stoop R, Thomas S, Rassendren F, Kawashima E, Buell G, Surprenant A, North RA (1999) Contribution of individual subunits to the multimeric P2X2 receptor: estimates based on methanethiosulfonate block at T336C. Mol Pharmacol 56:973-981. Medline

Surprenant A, Rassendren F, Kawashima E, North RA, Buell G (1996) The cytolytic P2Z receptor for extracellular ATP identified as a P2X receptor (P2X7). Science 272:735-738. CrossRef Medline

Tittle RK, Power JM, Hume RI (2007) A histidine scan to probe the flexibility of the rat P2X2 receptor zinc-binding site. J Biol Chem 282:19526-19533. CrossRef Medline

Virginio C, Church D, North RA, Surprenant A (1997) Effects of divalent cations, protons and calmidazolium at the rat $\mathrm{P} 2 \mathrm{X} 7$ receptor. Neuropharmacology 36:1285-1294. CrossRef Medline

Virginio C, MacKenzie A, North RA, Surprenant A (1999) Kinetics of cell lysis, dye uptake and permeability changes in cells expressing the rat P2X7 receptor. J Physiol 519:335-346. CrossRef Medline

von Kügelgen I, Harden TK (2011) Molecular pharmacology, physiology, and structure of the P2Y receptors. Adv Pharmacol 61:373-415. CrossRef Medline

Wilkinson WJ, Jiang LH, Surprenant A, North RA (2006) Role of ectodomain lysines in the subunits of the heteromeric $\mathrm{P} 2 \mathrm{X} 2 / 3$ receptor. Mol Pharmacol 70:1159-1163. CrossRef Medline

Yan Z, Khadra A, Li S, Tomic M, Sherman A, Stojilkovic SS (2010) Experimental characterization and mathematical modeling of $\mathrm{P} 2 \mathrm{X} 7$ receptor gating. J Neurosci 30:14213-14224. CrossRef Medline

Zimmermann H, Zebisch M, Sträter N (2012) Cellular function and molecular structure of ecto-nucleotidases. Purinergic Signal 8:437-502. CrossRef Medline 